\title{
Soft X-Ray Measurements of Z-Pinch-Driven Vacuum Hohlraums
}

K.L. Baker, ${ }^{\text {a) }}$ J.L. Porter, L.E. Ruggles, G.A. Chandler, Chris Deeney, M. Vargas, Ann Moats, Ken Struve, J. Torres, J. McGurn, W.W. Simpson and D.L. Fehl Sandia National Laboratory, Albuquerque NM, 87185

R.E. Chrien, W. Matuska and G.C. Idzorek

Los Alamos National Laboratory, Los Alamos NM, 87545

Abstract

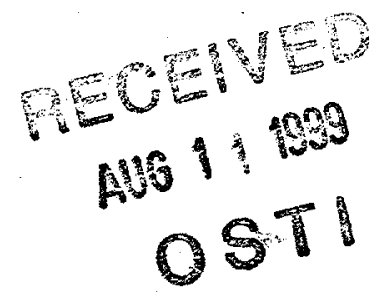

This article reports the experimental characterization of a z-pinch driven-vacuum hohlraum. We have measured soft $x$-ray fluxes of $5 \times 10^{12}$ $\mathrm{W} / \mathrm{cm}^{2}$ radiating from the walls of hohlraums which are $2.4-2.5 \mathrm{~cm}$ in diameter by $1 \mathrm{~cm}$ tall. The $\mathrm{x}$-ray source used to drive these hohlraums was a $\mathrm{z}$ pinch consisting of a 300 wire tungsten array driven by a $20 \mathrm{MA}, 100 \mathrm{~ns}$ current pulse. In this hohlraum geometry, the z-pinch $x$-ray source can produce energies in excess of $800 \mathrm{~kJ}$ and powers in excess of $100 \mathrm{TW}$ to drive these hohlraums. The $x$ rays released in these hohlraums represent greater than a factor of 25 in energy and more than a factor of three in $x$-ray power over previous laboratory-driven hohlraums.

PACS: 52.58.Ns, 52.55.Ez, 52.70La

a)Present address: University of California at Davis, Livermore, California 94551 


\section{DISCLAIMER}

This report was prepared as an account of work sponsored by an agency of the United States Government. Neither the United States Government nor any agency thereof, nor any of their employees, make any warranty, express or implied, or assumes any legal liability or responsibility for the accuracy, completeness, or usefuiness of any information, apparatus, product, or process disclosed, or represents that its use would not infringe privately owned rights. Reference herein to any specific commercial product, process, or service by trade name, trademark, manufacturer, or otherwise does not necessarily constitute or imply its endorsement, recommendation, or favoring by the United States Government or any agency thereof. The views and opinions of authors expressed herein do not necessarily state or reflect those of the United States Government or any agency thereof. 


\section{DISCLAIMER}

Portions of this document may be illegible in electronic image products. Images are produced from the best available original document. 
The indirect-drive approach to inertial confinement fusion ${ }^{1}$ utilizes hohlraums to improve the $x$-ray flux uniformity on fusion capsules. These hohlraums are composed of high- $\mathrm{Z}$ materials which effectively trap radiation, produce a more Plankian emission spectrum and, in the case of laser-driven hohlraums, convert a high percentage of laser light into soft $x$ rays. ${ }^{2,3}$ Hohlraums can be driven by a number of devices including lasers, z-pinches and heavy ion beams. To date, the most prevalent driver for hohlraum experiments has been the laser. A great deal of progress, however, has been made recently on z-pinch driven hohlraums.

In z-pinch driven vacuum hohlraums, the radiation source, a z-pinch, is located on the inside of the hohlraum itself as shown in Figure 1. The hohlraum is formed by enclosing a z-pinch in a current-return can consisting of a high atomic number material which then forms the walls of the hohlraum. A large current enters the hohlraum through the anode-cathode gap. The current travels up the wires of the z-pinch and returns down the interior of the hohlraum wall, leaving through the anode-cathode gap in which it entered. The current passing through the wires causes them to implode due to the radially inward $\mathrm{JxB}$ force. When the imploding plasma stagnates on the axis of the hohlraum, the resultant high density, high temperature plasma radiates in the soft $x$-ray regime. These soft $x$ rays are then used to drive the hohlraum. A typical surface area for a $z$-pinch hohlraum is $1700 \mathrm{~mm}^{2}$, considerably larger than laser-driven hohlraums which have surface areas of less than $15 \mathrm{~mm}^{2}$.

Z-pinches have been shown to convert their stored electrical energy into soft $x$ rays with an efficiency of greater than 15 percent. ${ }^{4,5}$ Until recently, these pinches have emitted their energy in a relatively long pulse width, which coupled with their large size in comparison to laser-driven 
hohlraums, could not produce hohlraums with radiation temperatures relevant to inertial confinement fusion. The $x$-ray powers have increased significantly with recent advances in load designs using increased wire numbers ${ }^{4,6,7}$ and multiple shells ${ }^{8-10}$ to reduce the magneto-Rayleigh-Taylor instability in these pinches. With this increase in $x$-ray power, $z$-pinches have become an attractive driver for indirect-drive capsule implosions and high energy density experiments. The energy deposited in these z-pinch driven hohlraums can be a factor of 30 or more greater than the energy deposited in current laser-driven hohlraums. The radiation temperature, $T$, driven in these hohlraums, however, is lower than the radiation temperatures driven in current laser driven hohlraums. This lower temperature is primarily due to the larger surface area, but it is also due to the longer time duration of the $x$-ray drive in z-pinch driven hohlraums. This temperature can be increased in a number of ways which include higher input power through further mitigation of the magneto-Rayleigh-Taylor instability, using mixtures of materials ${ }^{11}$ which contain complementary high and low spectral opacities in the hohlraum walls and by using alternative hohlraum configurations which drastically reduce the surface area of the hohlraum. This letter presents the characterization of hohlraums driven by Z-pinches.

The z-pinch driven vacuum hohlraums described in this article were 1 $\mathrm{cm}$ tall and 2.5-2.4 cm in diameter and contained one $4 \mathrm{~mm}$ diameter diagnostic hole. The wire array was composed of 300 tungsten wires which were varied between 11.5 and $12.2 \mathrm{~mm}$ in diameter on different shots for a combined mass of approximately 6 to $6.7 \mathrm{mg}$. The anode-cathode(A-K) gap in the hohlraums was also varied between $2.0-2.5 \mathrm{~mm}$ in diameter. The primary diagnostics, $x$-ray diodes, bolometer, and $x$-ray pinhole framing camera, viewed the wall of the hohlraum through a $4 \mathrm{~mm}$ hole at 40 degrees 
horizontally from normal to the center of the diagnostic hole and approximately 12 degrees in the vertical direction. All three diagnostics were located at a distance of $986 \mathrm{~cm}$ from the hohlraum wall which resulted in a solid angle of $2.07 \mathrm{e}-07 \mathrm{sr}$ for the bolometer and $5.17 \mathrm{e}-07 \mathrm{sr}$ for the $\mathrm{x}$-ray diodes.

The $x$ rays emitted from the diagnostic hole were measured with an array of four $\mathrm{x}$-ray diodes, a bolometer and a sixteen frame time-resolved $\mathrm{x}$-ray pinhole camera. The array of four $x$-ray diodes ${ }^{12}$ recorded the total $x$-ray power emitted from the diagnostic hole. The $x$-ray diode filter set included a $4.0 \mathrm{~mm}$ Kimfol filter, a $1.0 \mathrm{~mm}$ Vanadium filter, a $0.75 / 0.5 \mathrm{~mm}$ Zinc/Parylene_N filter and a 8.0/1.0 mm Beryllium/Parylene_N filter. The energy bins used in the $x$-ray diode unfolding to determine the total power were 137 to $284 \mathrm{eV}, 284$ to $513 \mathrm{eV}, 513$ to $1020 \mathrm{eV}$ and 1020 to $2300 \mathrm{eV}$. The bolometer ${ }^{13}$ was used to determine the total energy emitted from the hohlraum diagnostic hole and the time-resolved $\mathrm{x}$-ray pinhole camera was used to measure the spatial $\dot{x}$-ray flux emitted from the diagnostic hole at four separate time frames with each time frame containing four separate energy bins: The filter set for the pinhole camera included a $2.0 \mathrm{~mm}$ Boron filter, a 5.0/0.1 mm Parylene_N/Aluminum filter, a $1.0 \mathrm{~mm}$ Titanium filter and a 1.0 $\mathrm{mm}$ Chromium filter. The energy bins used in the pinhole camera unfolding were 80 to $188 \mathrm{eV}, 188$ to $285 \mathrm{eV}, 285$ to $460 \mathrm{eV}$ and 460 to $800 \mathrm{eV}$.

The pinhole camera by itself could not be absolutely calibrated because of the large dependence of the gain on the microchannel plate voltage coupled with the uncertainty in the pulser voltage. An unfolding was performed on the time-resolved pinhole camera using the four separate energy cuts at each time frame to determine the relative spatial flux profile. The bolometer's energy measurement was used to calibrate the $x$-ray power inferred from the array of $\mathrm{x}$-ray diodes and subsequently to absolutely calibrate 
the spatial flux unfolding of the pinhole camera images. ${ }^{14}$ Upon summing the flux over the image and normalizing to the power determined by the $x$ ray diode array and the bolometer, the absolute spatial flux profile was determined.

The incident radiation from the z-pinch, as well as joule heating from the current flow along the hohlraum wall, cause plasma to ablate from the hohlraum walls surrounding the diagnostic hole and partially obscure this diagnostic hole. This effective change in area can lead to an underestimation of the hohlraum wall temperature when non-imaging diagnostics such as $x-$ ray diodes and bolometers are used to determine power and later to infer a wall temperature assuming the original area of the diagnostic hole. By using the time-resolved pinhole camera in conjunction with the bolometer and the array of $\mathrm{x}$-ray diodes, the hole closure may be quantified.

This hole closure process is clearly seen in Figure 2 which shows line outs at four different time frames representing the unfolded flux profiles. This flux represents the radiation from the high $\mathrm{Z}$ gold wall of the hohlraum which has been partially absorbed by the carbon and hydrogen plasma filling the diagnostic hole, as well as the self-emission from the low $\mathrm{Z}$ carbon and hydrogen plasma. These line outs represent an average over a $700 \mathrm{~mm}$ vertical strip through the center of the diagnostic hole. The line outs clearly show hole closure is occurring. The initial time slice represented by the solid gray line occurs $1.6 \mathrm{~ns}$ before the peak emission of the $\mathrm{x}$-ray pulse. This displays the largest full-width-at-half-maximum (FWHM) of all of the profiles. The next time slice is centered $0.4 \mathrm{~ns}$ after the peak emission from the diagnostic hole and is shown as a dashed black line. This lineout has the greatest flux, however, because the hole is closing, the FWHM is less than the previous time slice. The third time frame is centered $2.4 \mathrm{~ns}$ after peak emission and is 
represented by the dashed gray line. The final solid black line in Figure 2 represents the profile $4.4 \mathrm{~ns}$ after peak emission. This line out has the smallest FWHM as expected due to hole closure.

The effective fractional area of the hole was also calculated from the measured pinhole camera images. The effective area is defined as the product of the pixel area and the flux summed over the entire image divided by the product of the average flux near the center of the hole and the area of the original hole. This can be expressed as

$$
\frac{A(t)}{A(0)}=\frac{A_{p} \sum_{i} F_{i}}{A(0) \sum_{c=1}^{n} F_{c} / n}
$$

where $A(t)$ is the time-dependent area of the hole with $A(0)$ being the initial area, $A_{p}$ is the area of an individual pixel, $F_{i}$ is the flux contained in pixel I and $F_{c}$ is the flux in pixel $c$ near the center of the hole. The numerator in Equation 1 is summed over the entire image while the sum in the denominator is taken over an area of approximately $0.4 \mathrm{~mm}^{2}$ located in the center of the hole.

Figure 3 shows the experimental hole closure results, as well as a simulation of the hole closure process. A two-dimensional radiation magneto-hydrodynamic code was used to simulate this process. The black line in Figure 3 represents a simulation of the effective open area of the hole as viewed through the parylene_N channel. The circles, squares, and diamonds represent reduced experimental data from three separate shots with each shot containing four frames separated in time by two nanoseconds. There is qualitative agreement between the simulation and the measured values, however, the slope or rate of closure is slightly different from the measured 
value. Figure 3 shows that the hole closes faster in the simulations than in the actual experiment. This Figure also shows that at peak emission, $t=0$, the hole has an effective area which is only 70 percent of the original area of the hole. In addition, it is clear that the area of the hole is decreasing rapidly in time. A least-squares fit to the three shots shown in the Figure 3 indicate that the area of the hole is decreasing at a rate of approximately 2.1 percent/ns near the time of peak emission.

Figure 4 shows the power as a function of time emitted through the diagnostic hole. The solid black line shows the unfolded power as determined from the bolometer-corrected $x$-ray diodes, not accounting for hole-closure. The open triangles represent the corrected power emitted from the diagnostic hole taking into account the hole-closure process. This was done by dividing the $x$-ray diode power by the effective fractional area of the hole shown in Figure 3 . The open circles are then taken from the flux line outs obtained in Figure 2. The maximum flux was taken from each time frame and converted to power by multiplying the flux by the original area of the hole, $0.126 \mathrm{~cm}^{2}$. The overlap of the circles and triangles illustrates the self-consistency of the analysis performed for this paper.

In summary, this letter presents the measured $x$-ray power driven in a vacuum $z$-pinch hohlraum. The power near peak $x$-ray emission was found to $5 \times 10^{12} \mathrm{~W}$ measured through a $4 \mathrm{~mm}$ diameter diagnostic hole. The diagnostic hole, through which the measurement were made, was partially closed during the measurement period. The partial closure of the diagnostic hole was determined to be approximately $30 \%$ at the time of maximum $x$-ray emission from the hohlraum which was found to be in reasonable agreement with two-dimensional radiation magneto-hydrodynamic simulations of the hole closure process. 
This work was performed under the auspices of the U.S. Department of Energy by the Sandia National Laboratory. Sandia is a multiprogram laboratory operated by Sandia Corporation, a Lockheed Martin Company, for the United States Department of Energy under contract DE-AC04-94AL85000. 


\section{REFERENCES}

1. John Lindl, Phys. Plasmas 2, 3933 (1995).

2. R. Sigel, G.D. Tsakiris, F. Lavarenne, J. Massen, R. Fedosejevs, K. Eidmann, J. Meyer-ter-Vehn, M. Murakami, S. Witkowski, H. Nishimura, Y. Kato, H. Takabe, T. Endo, K. Kondo, H. Shiraga, S. Sakabe, T. Jitsuno, M. Takagi, S. Nakai, C. Yamanaka, Phys. Rev. A 45, 3987 (1992).

3. Robert L. Kauffman, L.J. Suter, C.B. Darrow, J.D. Kilkenny, H.N. Kornblum, D.S. Montgomery, D.W. Phillion, M.D. Rosen, A.R. Thiessen, R.J. Wallace, and F. Ze, Phys. Rev. Lett. 73, 2320 (1994).

4. R.B. Spielman, C. Deeney, G.A. Chandler, M.R. Douglas, D.L. Fehl, M.K. Matzen, D.H. McDaniel, T.J. Nash, J.L. Porter, T.W.L. Sanford, J.F. Seamen, W.A. Stygar, K.W. Struve, S.P. Breeze, J.S. McGurn, J.A. Torres, D.M. Zagar, T.L. Gilliland, D.O. Jobe, J.L. McKenney, R.C. Mock, M. Vargas, T. Wagoner, D.L. Peterson, Phys. Plasmas 5, 2105 (1998).

5. M. Keith Matzen, Phys. Plasmas 4, 1519 (1997).

6. T. W. L. Sanford, G. O. Allshouse, B. M. Marder, T. J. Nash, R. C. Mock, R. B. Spielman, J. F. Seamen, J. S. McGurn, D. Jobe, T. L. Gilliland, M. Vargas, K. W. Struve, W. A. Stygar, M. R. Douglas, M. K. Matzen, J. H. Hammer, J. S. De Groot, J. L. Eddleman, D. L. Peterson, D. Mosher, K. G. Whitney, J. W. Thornhill, P. E. Pulsifer, J. P. Apruzese, Y. Maron, Phys. Rev. Lett. 77, 5063 (1996). 
7. C. Deeney, T.J. Nash, R.B. Spielman, J.F. Seamen, J.S. McGurn, D.O. Jobe, M. Vargas, T.L. Gilliland, R.C. Mock, K.W. Struve, K.G. Whitney, P.E. Pulsifer, J.P. Apruzese, J.W. Thornhill, and J. Davis, Phys. Plasmas 5, 2431 (1998).

8. C. Deeney, M.R. Douglas, R.B. Spielman, T.J. Nash, D.L. Peterson, P. L'Eplattenier, G.A. Chandler, J.F. Seamen, and K.W. Struve, Phys. Rev. Lett. 81, 4883 (1998).

9. R.B. Baksht, I.M. Datsko, V.I. Oreshkin, A.G. Russkikh, A.V. Fedyunin, A.V. Shishlov, M.O. Koshevoi, A.A. Rupasov, D.A. Fedin, and A.V. Shikanov, Plasma Physics Reports 22, 622 (1996).

10. J. Davis, N.A. Gondarenko, and A.L. Velikovich, Appl. Phys. Lett. 70, 170 (1997).

11. T.J. Orzechowski, M.D. Rosen, H.N. Kornblum, J.L. Porter, L.J. Suter, A.R. Thiessen, and R.J. Wallace, Phys. Rev. Lett. 77, 3545 (1996).

12. G.A. Chandler, J. Aubert, J. Bailey, A. Carlson, D. Derzon, M. Derzon, R. Dukhart, R. Humphreys, J. Hunter, D.J. Johnson, M.K. Matzen, A. Moats, R. Olson, J. Pantuso, P. Rockett, C. Ruiz, P. Sawyer, and J. Torres, Rev. Sci. Instrum. 63, 4828 (1992).

13. L.P. Mix, E.J.T. Burns, D.L. Fehl, D.L. Hanson, and D.J. Johnson, "Low Energy X-Ray Diagnostics," presented at the American Inștitute of Physics Conference Proceedings \#75, New York (American Institute of Physics, 1981), p. 25. 
14. K.L. Baker, J.L. Porter, L.E. Ruggles, D.L. Fehl, G.A. Chandler, M. Vargas, L.P. Mix, W.W. Simpson, Chris Deeney, R.E. Chrien, and G.C. Idzorek, Rev. Sci. Instrum. 70, 2012 (1999). 


\section{FIGURE CAPTIONS}

Figure 1 Z-pinch driven hohlraum configuration. Current enters the anodecathode gap and travels up the wires along the $z$-axis resulting in a magnetic field in the theta direction. The resultant $\mathrm{JxB}$ force causes the mass shell to implode radially inward.

Figure 2 Flux line outs of the unfolded pinhole camera images. The line outs are spaced $2 \mathrm{~ns}$ apart with the initial line out represented as a solid gray line. The second time frame is shown as a dashed black line with the third time frame drawn as a dashed gray line. The final time frame is displayed as a solid black line.

Figure 3 Fractional area as a function of time for three separate shots. The frames are taken $2 \mathrm{~ns}$ apart with time zero representing the maximum emission from the diagnostic hole measured by the $x$-ray diodes. The solid black line represents the calculated fractional area.

Figure 4 Comparison between unfolded power. The solid black line represents the unfolded $x$-ray diode power with no correction for hole closure. The open triangles represent the uncorrected $x$-ray diode power divided by the effective area shown in figure 3 . The open circles represent the maximum of the flux line outs shown in figure 2. Power was obtained by multiplying the flux by the original area of the hole, $0.126 \mathrm{~cm}^{2}$. 


\section{FIGURES}

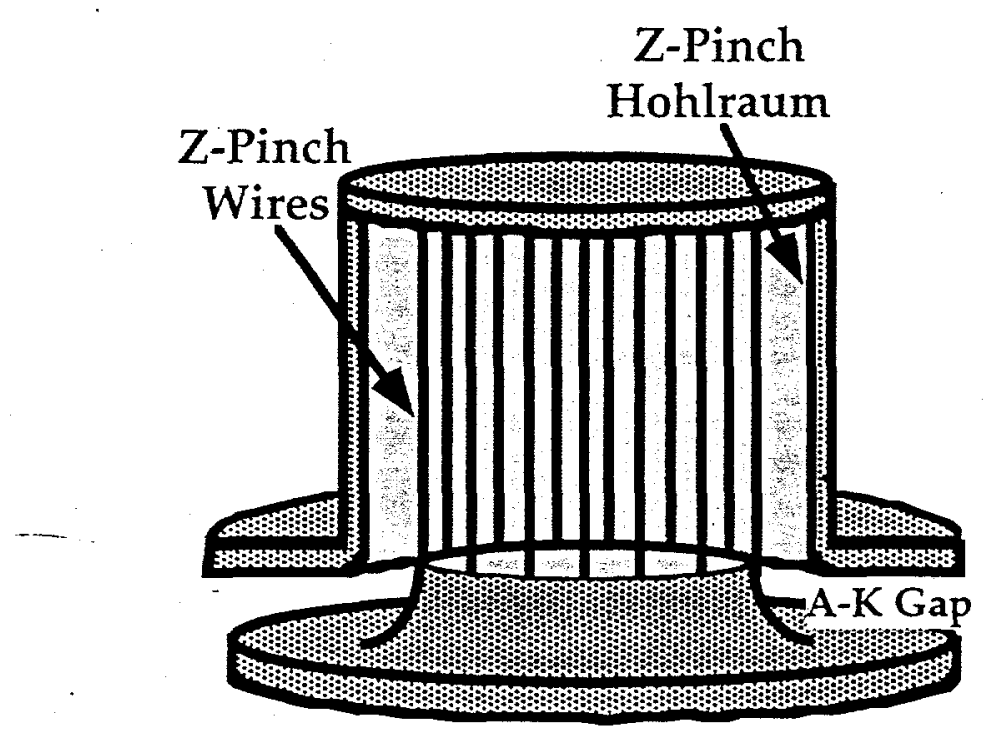

Figure 1

Kevin Baker 


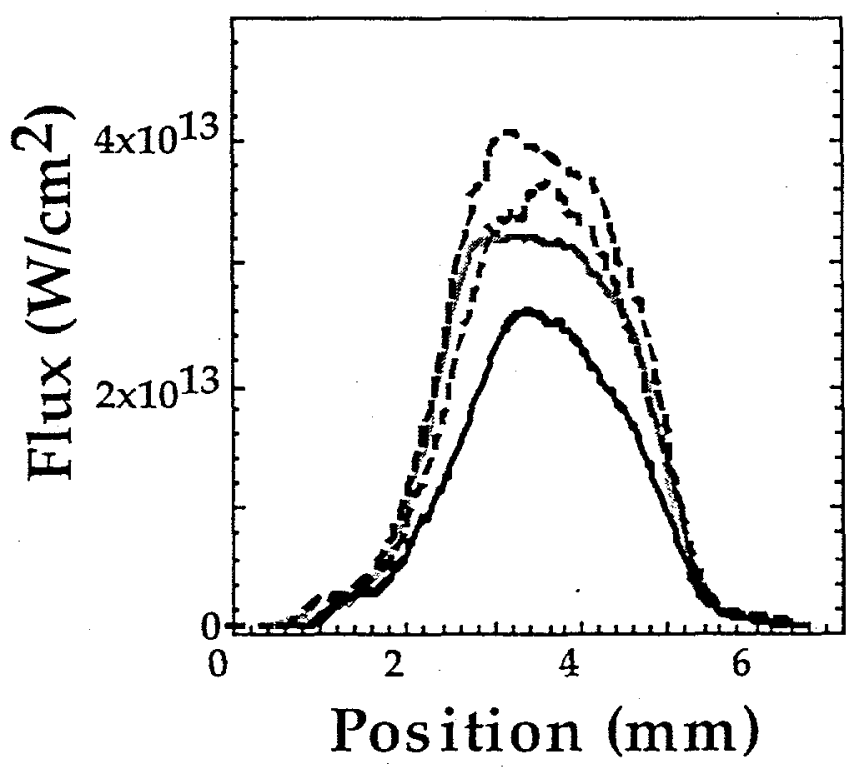

Figure 2

Kevin Baker 


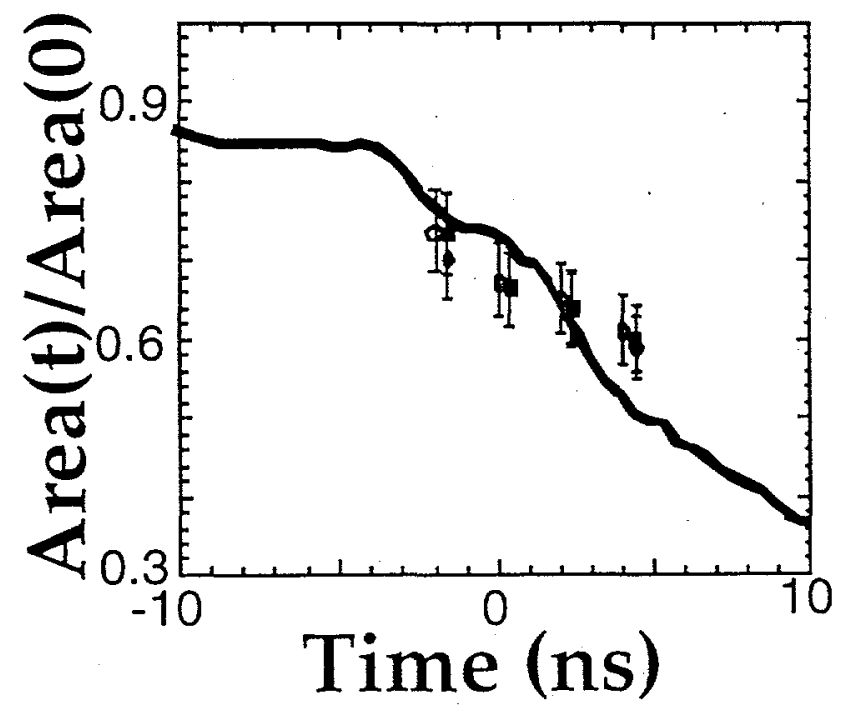

Figure 3

Keviñ-Baker 


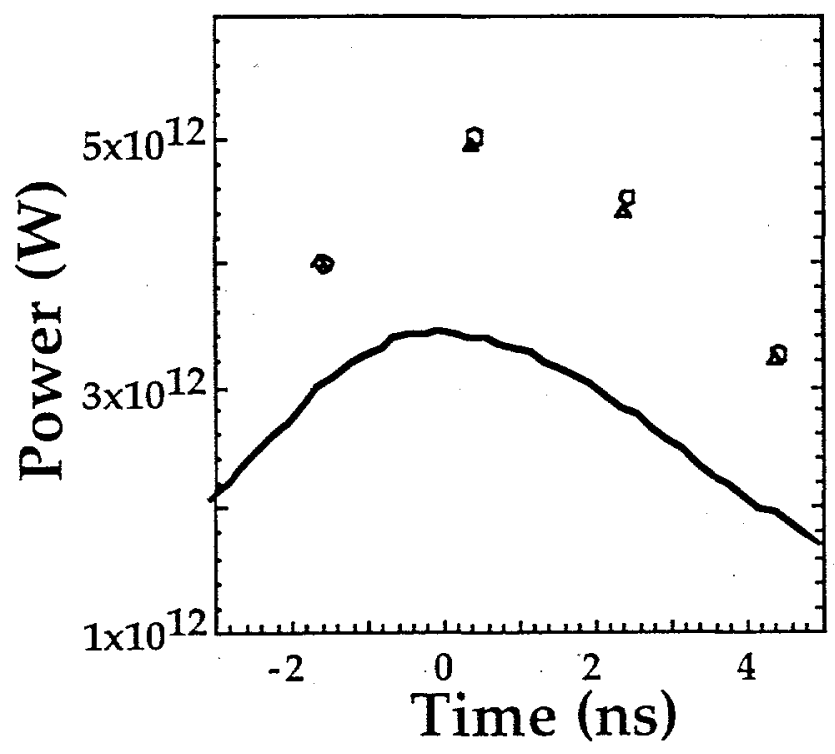

Figure 4

Kevin Baker 